\title{
Measurement of Work of Breathing in Infancy
}

\author{
G. M. STOKES, A. D. MILNER, ${ }^{(7)}$ F. JOHNSON, I. G. C. HODGES, AND R. C. GROGGINS \\ Department of Child Health, University of Nottingham Medical School, Queen's Medical Centre, Nottingham. \\ England
}

\begin{abstract}
Summary
Assessment of lung function in young children is extremely difficult unless sedation is given. If tidal exchange and intrathoracic pressure swings can be recorded, the severity of the respiratory problem can be measured by constructing pressure-volume loops and calculating the work of breathing. The system we have used to measure tidal thoracic volumes is that of a soft, rubber, inflatable jacket with pressure-volume characteristics linear from inflation pressure of 2.5 to $7 \mathrm{~cm} \mathrm{H}_{2} \mathrm{O}$. Oesophageal (intrathoracic) pressures are measured using water-filled nasogastric tubes (FG6). Frequency responses showed the $63 \%$ rise times for the jacket and water-filled nasogastric tube assessed together to be $10.5 \mathrm{msec}$. Recordings were traced onto a computer digitizing tablet and print-outs were obtained with the following information: respiratory rate, tidal thoracic volume, minute thoracic volume, oesophageal pressure, resistive work per min, elastic work per min, and total work per min. Comparisons were made between volumes measured using the respiratory jacket $\left(V_{J}\right)$ and by pneumotachograph and integrator $\left(V_{I n t}\right)$ in six infants.

Hysteresis arising from the jacket produces some change in resistive work of breathing, but the total work of breathing is only increased by a maximum of $10.5 \%$.

Studies on healthy newborn babies showed that the jacket system tends to underrecord the resistive work of breathing, but that total work of breathing values are very similar.

Reproducibility of analysis showed the following coefficients of variation from the mean: tidal thoracic volume, $1.6 \%$; minute thoracic volume, $1.7 \%$; resistive work, $5 \%$; elastic work, $2 \%$; and total work, $2.5 \%$. The extent of breath-to-breath variation is much larger. This system makes it possible to obtain serial measurements of work of breathing without the need for sedation in infants who may be acutely ill and in respiratory failure.
\end{abstract}

\section{Speculation}

Techniques are not available currently which allow us to study quantitatively the disturbances in lung mechanics which occur in respiratory failure in infancy. If we are to learn more about the natural history and response to a variety of therapeutic regimens, methods must be developed which allow us to study these children in greater detail without the need for sedation.

One possible approach is to measure the total work of breathing noninvasively using the respiratory jacket to measure thoracic volume change, and measuring intrathoracic pressure changes by filling the nasogastric feeding tube with water, connecting it to a pressure-transducer, and withdrawing the tube so that its tip lies in the lower oesophagus.

Assessment of lung function in young infants is extremely difficult. The warm, well-fed newborn is a self-sedating creature so that with care it is possible to obtain measurements of lung volumes and lung mechanics. Once beyond this stage little information can be collected unless sedation is given to enable the infant to tolerate a face mask (6). Because of this, only a small amount of data is available because parents are understandably reluctant to allow their healthy children to be studied if sedation is involved and the use of hypnotic drugs is contraindicated in the presence of respiratory failure.

If tidal exchange and intrathoracic pressure swings can be recorded, the severity of the respiratory problem can be measured by constructing pressure-volume loops and calculating the work of breathing. Figure 1 represents such a loop. The total work of breathing may be subdivided into: (1) the resistive work, i.e., the area represented by the loop, $\mathrm{ABCDA} ;(2)$ the elastic component, which is the area, AECFG. The line AEC represents the dynamic compliance.

The dimensions of work are "force $\times$ distance," which are equivalent to "pressure $\times$ volume," expressed either as gramcentimeters or joules $\left(1\right.$ joule $\left.=10^{5} \mathrm{~g} \cdot \mathrm{cm}\right)$.

Elastic work per breath may be calculated from the tidal volume and the compliance, although this ignores the rectangular area formed by the two sides GA and GF. Resistive work has been taken as the area within the pressure volume loop. The total work of breathing is the sum of the elastic and resistive work.

\section{MATERIALS AND METHODS}

TIDAL THORACIC VOLUMES

The system we have used to measure tidal thoracic volumes is that of a soft, rubber, inflatable jacket, as described by Milner in $1970(3)$ and $1971(4)$.

The jacket is made of thin $(0.4 \mathrm{~mm})$ soft, pure latex rubber. It may be worn by the infant in whatever position he is nursed. The jacket encompasses the chest and abdomen and fits snugly around the trunk and well up to the neck, the shoulder "straps" being secured by an adhesive strip (Fig. 2). In the present study, two sizes of jacket were used, one $30 \mathrm{~cm}$ length and $48 \mathrm{~cm}$ in circumference and the other $38 \mathrm{~cm}$ long with a circumference of $64 \mathrm{~cm}$. On the front of each jacket are two inlet ports to which tubing may be attached. The first port is joined by means of tubing and a $\mathrm{Y}$ connector to a water manometer and to a $50 \mathrm{ml}$ calibration syringe. The second port is linked by tubing to a pressure transducer (Pye Ether model U.P.I. $500 \mathrm{ohm}$ ) and a 2-channel Pen Recorder (Ormed type MX 212). (Fig. 2). The jacket is inflated to a pressure of 3 to $4 \mathrm{~cm} \mathrm{H}_{2} \mathrm{O}$. As the baby breathes, pressure changes of 1 to $2 \mathrm{~mm} \mathrm{H}_{2} \mathrm{O}$ are generated within the jacket. These pass to the pressure transducer enabling a trace of tidal thoracic volume to be obtained on one channel of the pen recorder. This volume is calibrated by alternatively injecting and withdrawing a known volume of air, e.g. $50 \mathrm{ml}$, from the jacket by means of the calibration syringe and measuring the changes in baseline position of the end tidal points (Fig. 3). This procedure is repeated until at least six reproducible calibrations are obtained.

The pressure-volume characteristics of the jackets are linear from an inflation pressure of $2.5 \mathrm{~cm} \mathrm{H}_{2} \mathrm{O}$ up to at least $7 \mathrm{~cm} \mathrm{H} \mathrm{H}_{2} \mathrm{O}$ (5). This constitutes the working range. Within this range, the dynamic properties of the jacket produce recordings with some hysteresis up to $60 \mathrm{cpm} \mathrm{(5).} \mathrm{At} \mathrm{rates} \mathrm{between} 60$ and $90 \mathrm{cpm}$, there is compression of the hysteresis curve. 


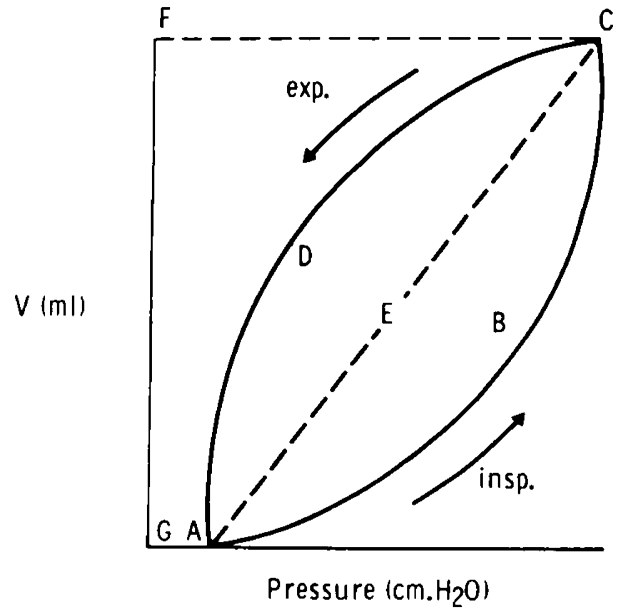

Fig. 1. Diagram of pressure-volume loop. Area ABCDA represents area of resistive work, area AECFG represents area of elastic work, and the line AEC represents compliance.

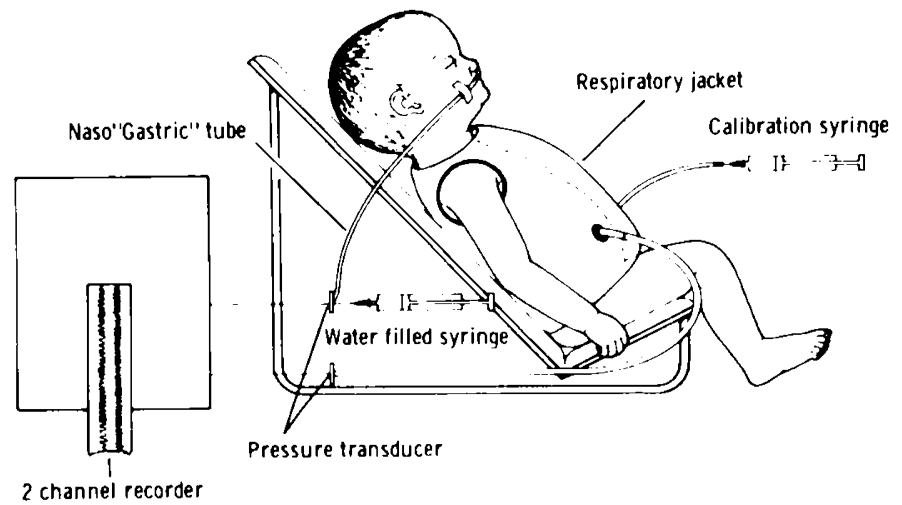

Fig. 2. Diagram of the system, showing the respiratory jacket and the nasogastric tube linked to the 2-channel Pen-Recorder via pressure transducers.

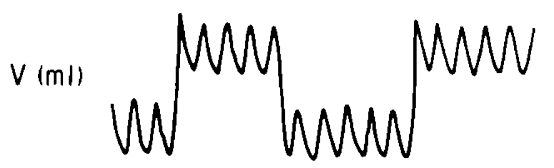

\section{ᄂนЦน}

Fig. 3. Volume calibration taken from the jacket, showing changes in baseline position of end-tidal points when $50 \mathrm{ml}$ are injected and withdrawn by a calibration syringe.

\section{ESOPHAGEAL PRESSURES}

Oesophageal (intrathoracic) pressures are measured using nasogastric feeding tubes (FG6). These are connected to a pressure transducer (Ormed type 524), gently flushed with water, and then carefully withdrawn from the stomach to a position 2 to $3 \mathrm{~cm}$ above the diaphragm. The pressure transducer is placed at approximately the same height as the tip of the nasogastric tube. Esophageal pressure swings are displayed on the second channel of the Pen Recorder.

\section{FREQUENCY RESPONSES}

The two pressure transducers were connected to a sealed, 3-liter glass container, the Pye Ether model by the jacket tubing and the Ormed model via the water-filled nasogastric tube, the latter inserted through a rubber bung so that its tip lay inside the container. A square-wave pressure change was produced by burst- ing a balloon inflated within the container, and the $63 \%$ rise times were taken from the 2 -channel recorder traces. The jacket was also inflated to a pressure of approximately $4 \mathrm{~cm} \mathrm{H}_{2} \mathrm{O}$ and placed around a balloon. The balloon was then burst, and the response time was measured as before.

\section{TIDAL VOLUME MEASUREMENTS}

Comparisons were made between volumes measured using the respiratory jacket $\left(\mathrm{V}_{\mathrm{J}}\right)$ and by face mask, pneumotachograph (Fleisch type 1), and electronic integrator (S.E. Labs EMMA) ( $\mathrm{V}_{\mathrm{Im}}$ ) on six infants (mean age, 5 months; range, $2 \frac{1 / 2}{2}$ to $6^{1 / 2}$ months). All were asymptomatic and had been sedated for lung function tests as part of a bronchiolitis follow-up study.

The dynamic properties of the jacket and the extent of the hysteresis were assessed by studying seven sedated infants, aged between 4 and 17 months, who were convalescent after acute bronchiolitis, but tended to be hyperinflated with thoracic gas volumes ranging from 30.1 to 85.5 (mean, 50.7 ) $\mathrm{ml} / \mathrm{kg}$ of body weight. On each occasion, the child, who was wearing a respiratory jacket, was nursed in a 260 liter body plethysmograph, and a face mask was placed on the child's face. A bias flow of air was conducted to the face mask from a tube passing through the wall of the body plethysmograph. Expiratory gases were conducted out via a second, wide-bore tube. The body box was then sealed, and the output from the pressure transducer connected to the jacket $\left(V_{\text {.J }}\right)$ was compared with the output from the transducer monitoring pressure inside the body box $\left(\mathrm{V}_{\mathrm{B}}\right)$ for at least six breaths.

Subsequently, the face mask was attached to a pneumotachograph, and records of jacket volume and volume measured by electronic integration were obtained. Curves were constructed from plethysmograph/jacket and integrated/jacket volume signals, and the phase shift at mid-volume points was calculated in each case.

\section{WORK OF BREATHING MEASUREMENTS}

Jacket volumes and esophageal pressure recordings were traced onto a computer digitizing tablet (Tektronix Tablet 4593 on line to a 4012 Graphics Terminal). Up to six pressure-volume loops were computed at any one time. Print-outs were obtained with the following information: respiratory rate, tidal thoracic volume. minute thoracic volume, oesophageal pressure, resistive work per min, elastic work per min, and total work of breathing per min.

\section{REPRODUCIBILITY OF ANALYSIS}

The accuracy of the computer digitizing process, including operator error, was assessed in four patients with acute severe bronchiolitis by analyzing the same breath five times and calculating the resulting coefficient of variation for each of the parameters measured.

\section{REPRODUCIBILITY OF INDIVIDUAL. BREATHS}

The extent of breath to breath variation in the parameters measured was assessed in four patients by computing individually six consecutive breaths from each patient and again calculating the coefficients of variation.

\section{EFFECT OF JACKET HYSTERESIS IN MEASUREMENT OF BREATHING}

The error in the measurement of total work of breathing introduced by the hysteresis of the jacket was assessed in two ways:

(1) Sine wave curves simulating pressure and volume signals were traced on to the Tektronix tablet positioned to create a progression of phase shifts, commencing at $180^{\circ}$, equivalent to zero phase shift between pressure and volume.

(2) Six healthy, full-term infants, aged between 3 and $10 \mathrm{hr}$, were studied using a respiratory jacket and a pneumotachograph mounted in a face mask. Intrathoracic pressures were mea- 
sured as before via a 6FG nasogastric feeding tube. Comparisons of tidal exchange and work of breathing were obtained from the two volume measurement systems.

\section{RESULTS}

\section{FREQUENCY RESPONSES}

The $63 \%$ rise time for the Pye Ether pressure transducer was 10 msec, a $3 \mathrm{~dB}$ loss at $16 \mathrm{~Hz}$, whereas the $63 \%$ rise times for the jacket and water-filled nasogastric tube assessed together were identical at $10.5 \mathrm{msec}$, a $3 \mathrm{~dB}$ loss at $15 \mathrm{~Hz}$. When a $50 \mathrm{~cm}$ FG8 extension tube was added between the nasogastric tube and the transducer, no measurable difference from the previous results was obtained.

\section{TIDAL VOLUME MEASUREMENTS}

Measurements of tidal thoracic volume $\left(V_{J}\right)$ and tidal mouth volume $\left(\mathrm{V}_{\mathrm{Int}}\right)$ of 37 breaths in six asymptomatic infants correlated closely with an $r$ value of 0.98 , slope of 1.019 , and intercept of $1.887 \mathrm{ml}$ (Fig. 4).

On no occasion was a phase shift greater than $3.8^{\circ}$ (range, 1.6 to $3.8^{\circ}$; mean, $2.4^{\circ}$ ) seen between volumes measured by respiratory jacket and by body plethysmograph. Conversely, phase shifts up to $17.7^{\circ}$ (mean, $11.9^{\circ}$; range, 6.7 to $17.7^{\circ}$ ) were found between jacket volume and integrated volume (Fig. 5).

\section{REPRODUCIBILITY OF ANALYSIS}

Repeated measurements of oesophageal pressure and respiratory rate from the same breath were identical using the computer readout, which gives a record of integer values. For other parameters, the coefficients of variation from the mean were tidal thoracic volume, $1.6 \%$; minute thoracic volume, $1.7 \%$; resistive work of breathing per $\min , 5 \%$; elastic work per $\min , 2 \%$; and total work per $\min , 2.5 \%$.

\section{REPRODUCIBILITY OF INDIVIDUAL BREATHS}

In some babies with bronchiolitis, the breathing was regular

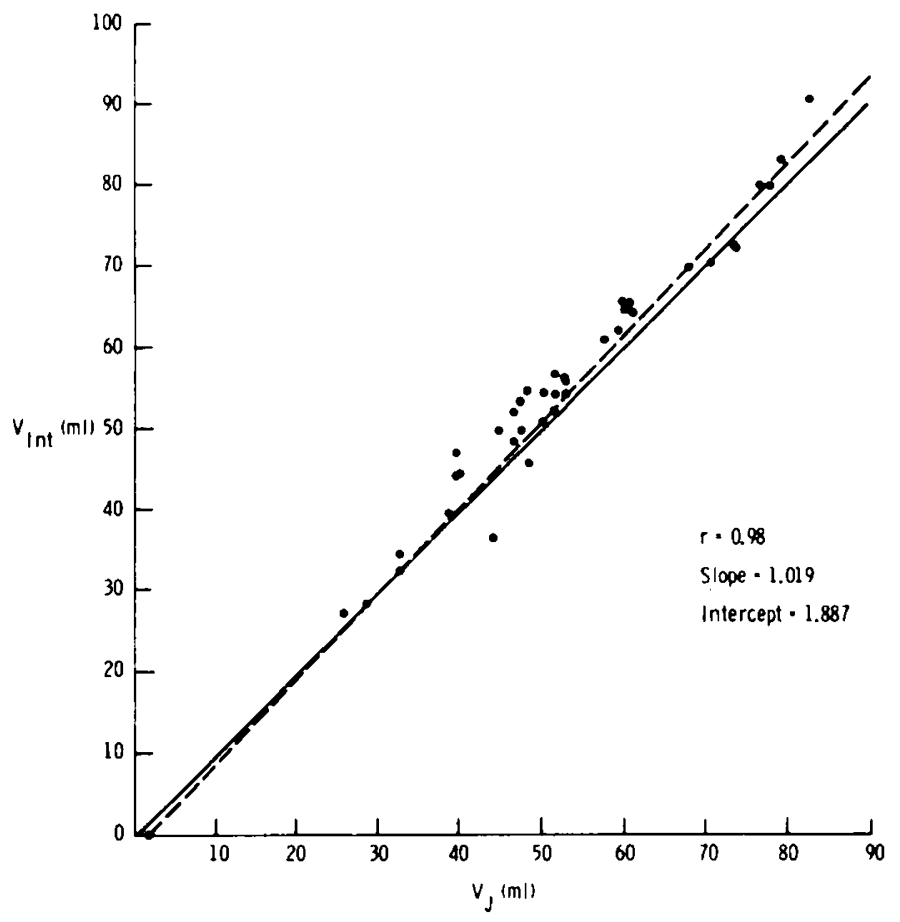

Fig. 4. Comparisons of $V_{I n t}$ and $V_{J}$ in six asymptomatic infants.

A. Jacket volume $\left(V_{\mathrm{J}}\right)$ and plethysmograph volume $\left(V_{B}\right)$

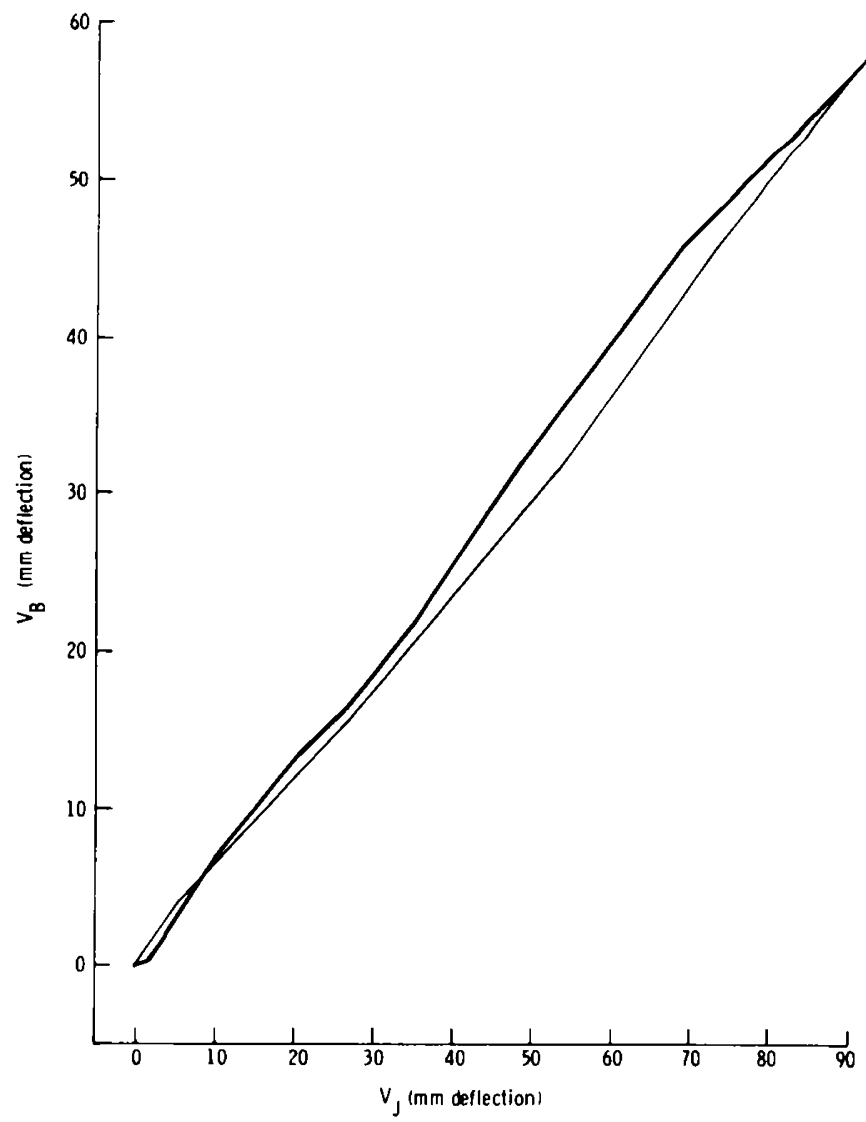

B. Jacket volume $\left(\mathrm{V}_{\mathrm{J}}\right)$ and integrated volume $\left(\mathrm{V}_{\mathrm{Int}}\right)$

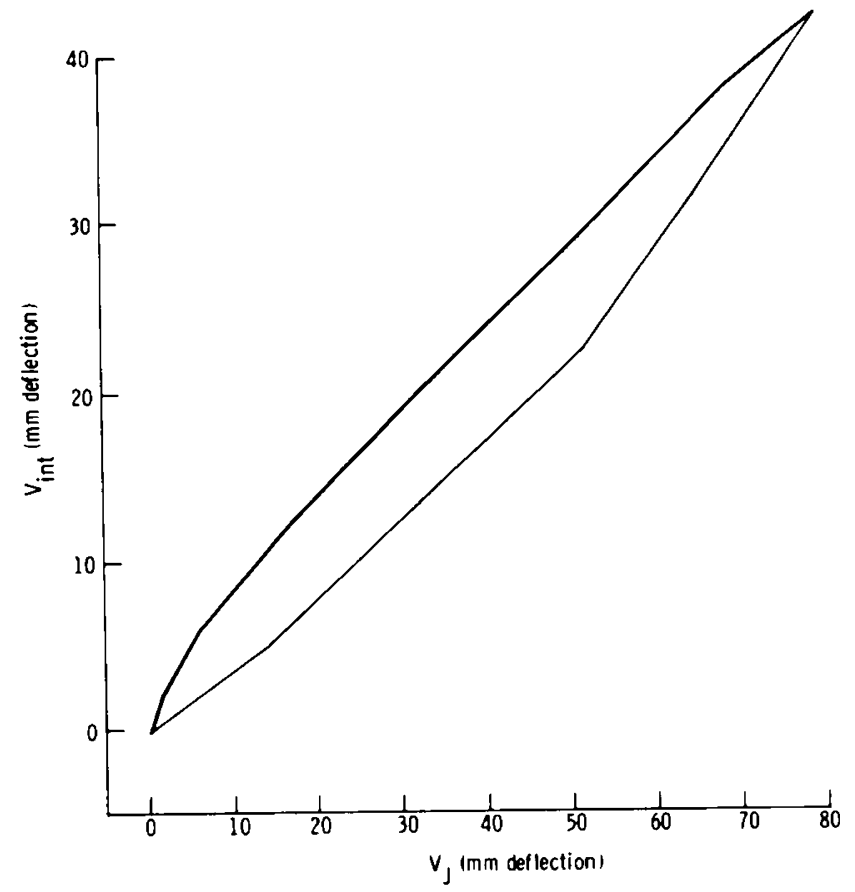

Fig. 5. Example of phase shifts in an infant who is hyperinflated after acute bronchiolitis. 
Table 1. Calculated parameters of lung function in patient $R$. O. showing little breath-to-breath variation

\begin{tabular}{|c|c|c|c|c|c|c|}
\hline Breath & $\begin{array}{c}\text { Esophageal } \\
\text { pressure } \\
\left(\mathrm{cm} \mathrm{H}_{2} \mathrm{O}\right)\end{array}$ & $\begin{array}{l}\text { Tidal thoracic } \\
\text { volume } \\
(\mathrm{ml})\end{array}$ & $\begin{array}{c}\text { Minute thoracic } \\
\text { volume } \\
(\mathrm{ml})\end{array}$ & $\begin{array}{c}\text { Resistive work } \\
\text { of breathing per } \\
\text { min } \\
(\mathrm{g} \cdot \mathrm{cm})\end{array}$ & $\begin{array}{c}\text { Elastic work of } \\
\text { breathing per } \\
\min \\
(\mathrm{g} \cdot \mathrm{cm})\end{array}$ & $\begin{array}{c}\text { Total work of } \\
\text { breathing per } \\
\text { min } \\
(\mathrm{g} \cdot \mathrm{cm})\end{array}$ \\
\hline 1 & 18 & 31 & 1327 & 8583 & 11986 & 20569 \\
\hline 2 & 20 & 32 & 1224 & 11621 & 12240 & 23860 \\
\hline 3 & 18 & 26 & 1109 & 8182 & 9754 & 17936 \\
\hline 4 & 19 & 27 & 1098 & 8490 & 10565 & 19055 \\
\hline 5 & 20 & 31 & 1376 & 10967 & 13619 & 24586 \\
\hline 6 & 19 & 35 & 1408 & 12878 & 13233 & 26111 \\
\hline
\end{tabular}

Table 2. Calculated parameters of lung function in patient $H$. G. showing a wide scatter of values

\begin{tabular}{|c|c|c|c|c|c|c|}
\hline Breath & $\begin{array}{c}\text { Esophageal } \\
\text { pressure } \\
\left(\mathrm{cm} \mathrm{H}_{2} \mathrm{O}\right) \\
\end{array}$ & $\begin{array}{c}\text { Tidal thoracic } \\
\text { volume } \\
(\mathrm{ml})\end{array}$ & $\begin{array}{c}\text { Minute thoracic } \\
\text { volume } \\
(\mathrm{ml})\end{array}$ & $\begin{array}{c}\text { Resistive work } \\
\text { of breathing per } \\
\text { min } \\
(\mathrm{g} \cdot \mathrm{cm})\end{array}$ & $\begin{array}{c}\text { Elastic work of } \\
\text { breathing per } \\
\min \\
(\mathrm{g} \cdot \mathrm{cm})\end{array}$ & $\begin{array}{l}\text { Total work of } \\
\text { breathing per } \\
\text { minute } \\
(\mathrm{g} \cdot \mathrm{cm})\end{array}$ \\
\hline 1 & 18 & 60 & 2125 & 8348 & 19202 & 27550 \\
\hline 2 & 27 & 71 & 2117 & 13674 & 28274 & 41948 \\
\hline 3 & 21 & 68 & 2900 & 9796 & 30583 & 40379 \\
\hline 4 & 19 & 72 & 3734 & 9667 & 35365 & 55032 \\
\hline 5 & 13 & 79 & 4099 & 168 & 25964 & 26132 \\
\hline 6 & 17 & 57 & 2843 & 8765 & 24107 & 32872 \\
\hline
\end{tabular}

Table 3. Coefficients of variation from the mean, expressed as percentages, of measured parameters from six consecutive breaths computed separately in four patients and the overall means of the group

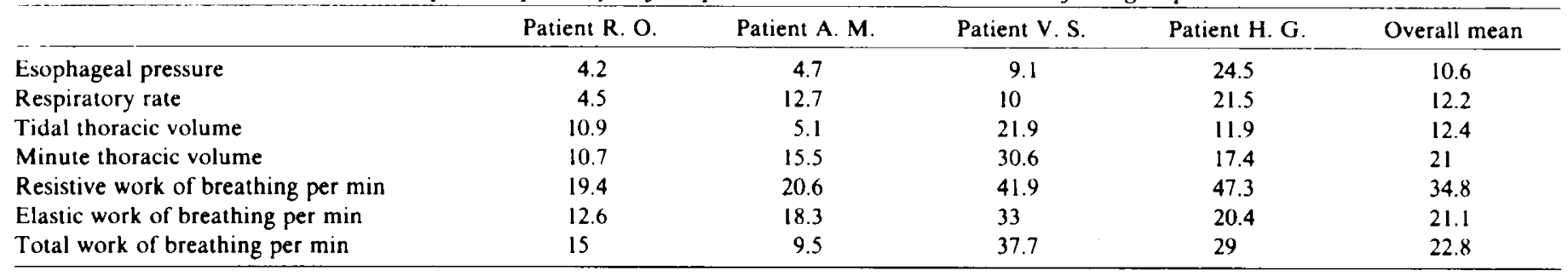

with little breath-to-breath variation. In others, breathing was erratic with a wide scatter of values (Tables 1 and 2). The coefficients of variation between breaths from the four patients studied are shown in Table 3 and Figures 6 and 7).

\section{EFFECT OF JACKET HYSTERESIS ON MEASUREMENT OF} BREATHING

As the phase shift between the two sine waves was increased from the position simulating zero resistance, the resistive work of breathing component rose rapidly whereas there was little initial fall in the elastic component. Subsequently, the rate of rise in resistive work was matched more closely by the rate of fall in elastic work. However, at zero phase shift, there is theoretically no contribution from the resistive component, so that a phase shift of $5^{\circ}$ will produce an increase in total work not exceeding $14 \%$ despite the dramatic rise in resistive work (Fig. 8). A $5^{\circ}$ phase shift superimposed on a shift between pressure and volume due to airways resistance will produce a reduced error.

Work of breathing values in the six neonates using jacket volume and integrated volume measurements were very similar, as shown in Table 4.

\section{DISCUSSION}

The problem of assessing lung function in sick infants and the resulting gaps in our knowledge are well known. Use of our system has made it possible to go some way towards bridging that gap.

Oesophageal pressures can be measured with little difficulty provided that the passing of a nasogastric tube can be justified clinically. The tubes must be gently perfused with water to prevent the formation of air bubbles, which occur particularly when the infant coughs. If bubbles are allowed to remain, the resulting signal is damped. When used in the manner described, the frequency responses are sufficiently good to prevent damping problems.

The respiratory jackets chosen were made of pure Latex rubber ensuring linearity of measurements and distortion-free records within the working range $(4,5) .{ }^{1}$ This is different from the experience of Kattan et al. (2) who, when using a polyurethanecoated nylon jacket, found that pressures correlated with volumes on a semi-logarithmic rather than a linear scale. The mechanical characteristics of the nylon also produced consistent errors in volume calibrations, which do not occur in the rubber jackets we used (2).

To describe tidal exchange more adequately we have differentiated between tidal thoracic volume (measured by respiratory jacket) and tidal mouth volume (measured by pneumotachograph and integrator). In health, both these measured parameters correlate closely and are virtually interchangeable, although $V_{J}$ studies have the decided advantage that they can be carried out in all circumstances without sedation.

In health, the work of breathing may be calculated by using either thoracic or mouth volumes. In the presence of airway obstruction, although mouth volume will provide a more accurate indication of tidal exchange, we believe that thoracic volume is the more appropriate parameter to use when measuring the energy cost of breathing. This can be demonstrated by considering a case of virtually complete airway obstruction; hardly any volume change would be measured at the mouth, suggesting very little

${ }^{1}$ Similar jackets may be obtained from Kastley Ltd.. P.O. Box 24, Blackburn, Lancashire, England. 
"work," whereas in reality, the child would be making huge respiratory "efforts" in an attempt to overcome the obstruction, and it is these very real efforts which would be more accurately recorded by changes in jacket volume.

The presence of severe airways obstruction inevitably produces large phase shifts between tidal thoracic volume and tidal volume at the mouth due to alveolar pressure fluctuations. Under these circumstances, the jacket signal will tend to exceed tidal exchange. We were concerned that the hysteresis in the jacket might significantly distort the resulting signal, but were reassured by the fact that the phase shift between the volume change measured by the jacket and by the body plethysmograph was less than $3.8^{\circ}$ in the seven babies studied.

When discussing the work of breathing, it is customary to divide the total work performed into its elastic and resistive components. Using the jacket system, it is impossible to separate the two when airways obstruction exists. In this situation, an increasing phase shift occurs between thoracic and mouth volumes, and end-tidal points measured by the jacket will not occur at the same time as zero flow at the mouth. This means that the pressure-volume loop, ABCDA (Fig. 1) includes an element of compliance as well as resistance and the area measured for elastic work. AECFG (Fig.

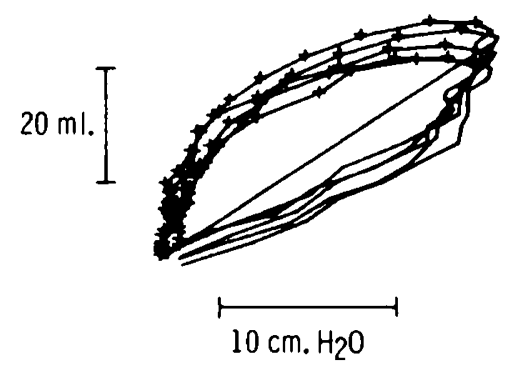

Fig. 6. Computer print-out of six pressure-volume loops in patient $R$ O. showing little breath-to-breath variation.

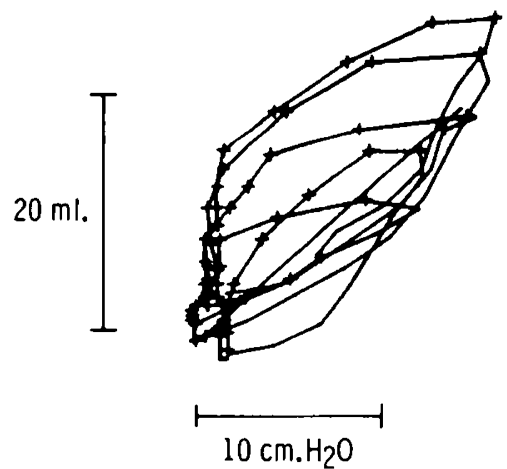

Fig. 7. Computer print-out of six pressure-volume loops in patient $\mathbf{H}$. G. showing a wide scatter of values.
1) contains a resistive as well as a compliant element. Nevertheless, when added together a valid representation of total work is obtained.

When carrying out jacket studies care must be taken to avoid artefacts. Happy infants love to "pluck" the jacket with their fingers and kick their legs about with "joie de vivre." These activities, like crying, sighing, coughing, and moving, serve to distort the trace.

We also found the jacket produced grossly distorted and exaggerated tidal volumes in a small group of children who either had severe airway obstruction and had been sedated or who had severe upper airways obstruction and adopted a pattern of breathing with tracheal tug and body rocking movements (Fig. 9). We have not observed this in any unsedated child with severe respiratory problems.

We were also worried that hysteresis arising from the jacket might have a significant distorting effect on work of breathing

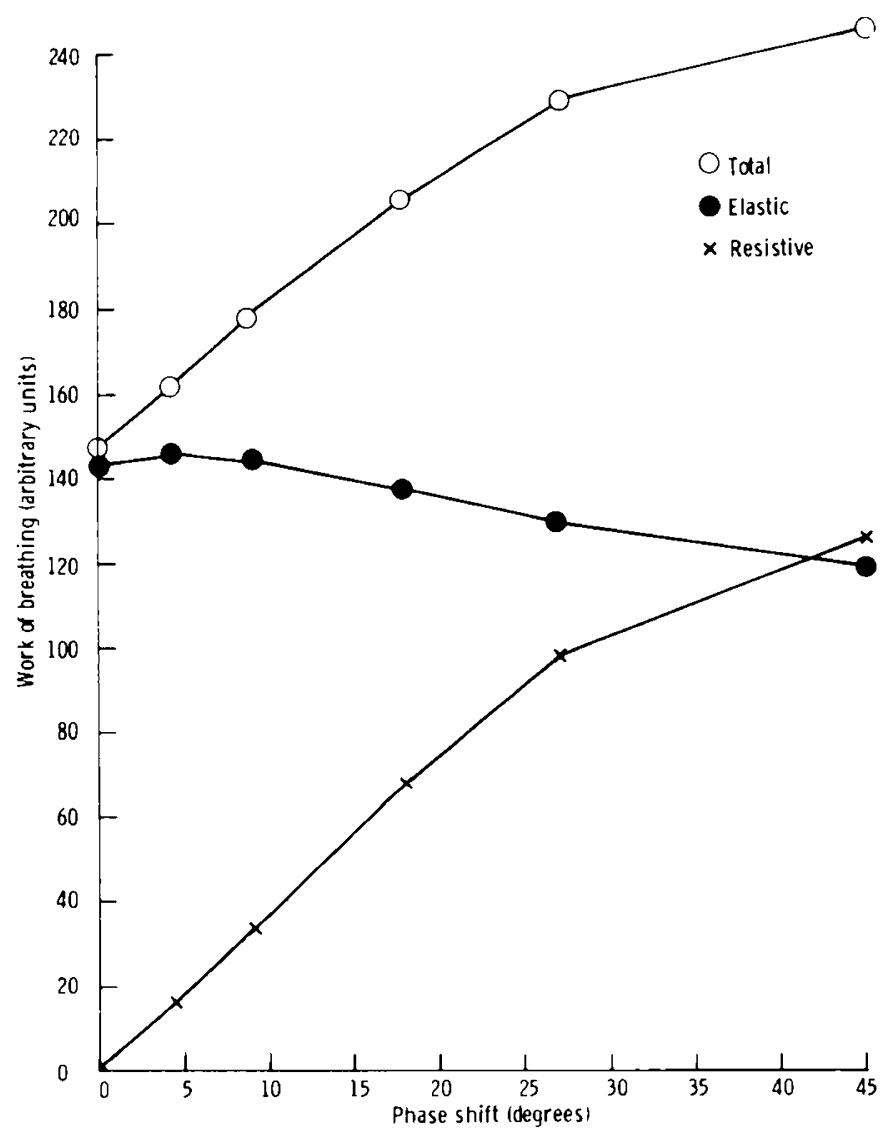

Fig. 8. Changes in resistive, elastic, and total "work" resulting from phase shift between two sine waves simulating pressure and volume curves.

Table 4. Calculated work of breathing results in six neonates using volumes measured by respiratory jacket and by electronic integration

\begin{tabular}{|c|c|c|c|c|c|c|c|c|}
\hline & \multicolumn{2}{|c|}{$\begin{array}{l}\text { Tidal volume } \\
(\mathrm{ml})\end{array}$} & \multicolumn{2}{|c|}{$\begin{array}{c}\text { Resistive work of } \\
\text { breathing } \\
(\mathrm{g} \cdot \mathrm{cm})\end{array}$} & \multicolumn{2}{|c|}{$\begin{array}{l}\text { Elastic work of } \\
\text { breathing } \\
(\mathrm{g} \cdot \mathrm{cm})\end{array}$} & \multicolumn{2}{|c|}{$\begin{array}{l}\text { Total work of } \\
\text { breathing } \\
(\mathrm{g} \cdot \mathrm{cm})\end{array}$} \\
\hline & $V_{.1}$ & $V_{\text {tat }}$ & $V_{. j}$ & $V_{\mathrm{Int}}$ & $V_{.1}$ & $V_{\ln x}$ & $V_{\text {.J }}$ & $V_{\mathrm{ln}}$ \\
\hline 1 & 27 & 29 & 573 & 971 & 1356 & 1442 & 1929 & 2413 \\
\hline 2 & 24.5 & 25 & 2459 & 3165 & 2971 & 3022 & 5430 & 6187 \\
\hline 3 & 28 & 31 & 3041 & 3663 & 3334 & 3638 & 6375 & 7301 \\
\hline 4 & 17 & 14 & 4094 & 4026 & 4763 & 3897 & 8857 & 7927 \\
\hline 5 & 28 & 28 & 2083 & 2376 & 4882 & 4662 & 6765 & 7038 \\
\hline \multirow[t]{2}{*}{6} & 18 & 21 & 1270 & 1634 & 1478 & 1684 & 2748 & 3318 \\
\hline & $23 \pm 4.9^{1}$ & $23.4 \pm 6.5$ & $2509 \pm 1258$ & $2878 \pm 1133$ & $3290 \pm 1398$ & $3158 \pm 1129$ & $5799 \pm 2547$ & $6036 \pm 2101$ \\
\hline
\end{tabular}

\footnotetext{
${ }^{1}$ Mean \pm S.D.
} 


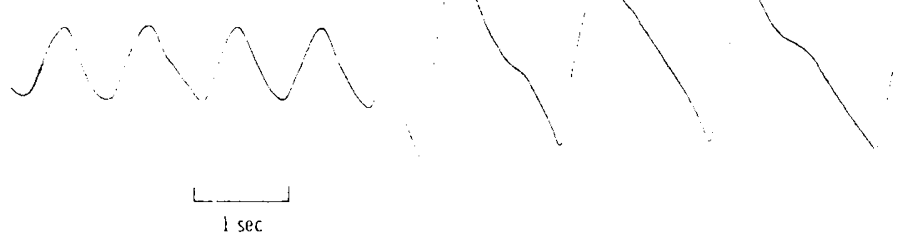

fig. 9. Examples of $(a)$ normal respiration and $(b)$ artefact produced by body rocking movements, seen occasionally in sedated children with severe respiratory problems. In tidal volumes recorded by respiratory jacket.

results. The measurements using the sine wave curves indicated that although the phase shift of $6^{\circ}$ seen in dynamic pressurevolume studies with the jacket at rates of up to 60 breaths per min (5) will produce large changes in resistive work of breathing, the total work of breathing will only increase by a maximum of $15 \%$. In practice, a phase shift of less than $4^{\circ}$ was found comparing the jacket volume $\left(V_{1}\right)$ and plethysmograph volume $\left(V_{B}\right)$ signals, equivalent to an error of $10.5 \%$. In addition, phase shift introduced by alveolar pressure changes will tend to reduce the error further.

The jacket studies on the healthy newborn babies showed, as expected, that the jacket does tend to underrecord the resistive work when compared with volume integration method, but that total work of breathing values are comparable in the absence of significant airways obstruction. The small, but measurable degree of error which occurs when transferring data into the computer could be avoided if magnetic tape were used for the initial records. This should be possible if on-line computer links are available.

There are sometimes large breath-to-breath variations in measurements of work of breathing. These can lead to problems of interpretation. Serial studies over longer periods of time and in the various sieep states will give more reliable information.

Thus, the respiratory jacket used in conjunction with a waterfilled nasogastric feeding tube allows us to measure total work of breathing in infants without the need for sedation. Errors introduced by the hysteresis of the jacket are small, particularly when compared with the wide range of values observed between health and severe airway obstruction.

This now allows us to study the natural history, the effects of drugs, and other aspects of management during the acute phase of severe respiratory problems.

\section{REFERENCES AND NOTES}

1. Cotes. J. E.: L.ung function-assessment and application in medicine. Ed. 3. Chap 4. P94 (Blackwell Scientific Publications, Oxford. 1975).

ᄀ. Kattan M Miyasaka. K. Voleyesi (;.. and Froese. A. B. A respiratory jacket for ventilatory measurements in children. J. Appl. Physiol. Respir. Environ Exercise Physiol., 45: 630 (1978).

3. Milner, A. D.: The respiratory jacket, a new method for measuring respiration Lancet. 2: 80 (1970).

4. Milner. A. D.: The respiratory jacket: A new method for measuring respiratory function in childhood and infancy. (M.D. Thesis, University of Cambridge. 1971).

5. Taylor, B., Helms, P., Hatch. D.. and Milner. A. D.: A rubber respiratory jacket for lung function testing in infants and young children. (in preparation).

6. Wohl, M. E. B.: Present capacity to evaluate pulmonary function relevant to bronchiolitis. Pediatr. Res.. 11: 252 (1977).

7. Requests for reprints should be addressed to: Dr. A. D. Milner, Reader in (hild Health. Medical School, Queens Medical Centre. Nottingham, England.

8. This research was supported by the Asthma Research Council

9. Received for publication January 3. 1980.

10. Accepted for publication June 23, 1980. 